\title{
Estrategias de afrontamiento a la sobrecarga de cuidadores de pacientes con enfermedad renal en diálisis
}

\author{
Camille Reyes-Vega ${ }^{1}$, Marta Rivero-Méndez ${ }^{2}$
}

${ }^{1}$ Universidad de Puerto Rico. Recinto de Ciencias Médicas. Puerto Rico

${ }^{2}$ Facultad de Escuela de Enfermería. Programa Graduado de la Universidad de Puerto Rico. Recinto de Ciencias Médicas. Puerto Rico

Como citar este artículo:

Reyes-Vega C, Rivero-Méndez M. Estrategias de afrontamiento a la sobrecarga de cuidadores de pacientes con enfermedad renal en diálisis. Enferm Nefrol. 2021 Abr-Jun;24(2):149-61

\section{Resumen}

Introducción: Asumir el rol de cuidadores familiares hacia personas con enfermedad renal y en diálisis por tiempo prolongado puede conllevar a agotamiento psicológico que hace a la persona inoperante y emocionalmente inestable; perjudicando su salud y la del receptor del cuidado.

Objetivo: Explorar las estrategias de afrontamiento y el contexto en que son implementadas por los cuidadores familiares de pacientes con enfermedad renal en tratamiento de diálisis para lidiar con la sobrecarga.

Material y Método: Estudio cualitativo con diseño fenomenológico-descriptivo con entrevistas semi-estructuradas individuales. Se utilizó la Escala de Sobrecarga del Cuidador de Zarit para determinar inicialmente la sobrecarga de los cuidadores familiares. Se seleccionaron por conveniencia 4 cuidadores familiares con puntuaciones de carga intensa mayores ( $>56$ puntos). Se recogieron datos sociodemográficos. Se realizó análisis temático según el método fenomenológico de Colaizzi.

Resultados: Se identificaron 6 temas principales: Inicio como cuidadores familiares, Vivencias como cuidadores familiares, Perspectivas como cuidadores familiares, Sobrecarga y Estrategias de afrontamiento, Necesidades de cuidadores familiares y Receptor del cuidado.

\section{Correspondencia:}

Camille Reyes Vega

E-mail: camille.reyes1@upr.edu / rvcamille74@gmail.com
Las estrategias de afrontamiento adaptativas incluyeron: ejercicios de respiración, oración y tejer. Los cuidadores también se enfrentan a una constante de sentimientos para dejarlo todo, evitar la comunicación y recurrir a conductas de riesgo.

Conclusiones: Las vivencias de cuidadores familiares requieren de un equipo interprofesional que implemente intervenciones para aliviar la carga de los cuidadores y que estos amplíen su marco de estrategias para mejorar la calidad de vida del receptor del cuidado en el hogar.

PALABRAS CLAVE: cuidadores; enfermedad renal; diálisis; sobrecarga; estrategias de afrontamiento; fenomenología.

\section{Coping strategies to the burden of caregivers of patients with kidney disease on dialysis}

\section{Abstract}

Introduction: Assuming the role of family caregivers for a prolonged period of people with kidney disease and on dialysis can lead to psychological exhaustion that makes the person inoperative and emotionally unstable; harming the health of the caregiver and the person cared for.

Objective: To explore the coping strategies and the context in which they are implemented by family caregivers of patients with kidney disease undergoing dialysis treatment to deal with overload. 
Material and Method: Qualitative study with a descriptive-phenomenological design using individual semi-structured interviews. The Zarit Caregiver Burden Scale was used to initially determine the overload of family caregivers. Four family caregivers with higher heavy burden scores ( $>56$ points) were selected at convenience. Sociodemographic data were collected. Thematic analysis was carried out according to the Colaizzi's phenomenological method.

Results: Six main themes were identified: Starting as family caregivers, Family caregiver's experiences, Perspectives as family caregivers, Overload and coping strategies, Needs of family caregivers and Care recipient. Adaptive coping strategies included: breathing exercises, prayer, and knitting. Caregivers also face a constant feeling of leaving everything, avoiding communication, and engaging in risky behaviors.

Conclusions: Family caregiver's experiences require an interprofessional team to implement interventions to alleviate caregiver burden and thus broaden their framework of strategies to improve the quality of life of the home care recipient.

KEYWORDS: caregiver; renal disease; dialysis; overload; coping strategies; phenomenology.

\section{Introducción}

La enfermedad renal representa un problema de salud pública global. Puerto Rico, contexto de esta investigación, ocupa la tercera posición en el mundo debido a la ocurrencia de casos de diálisis ${ }^{1}$. Ante estas estadísticas, es de esperarse que aumente el número de cuidadores familiares. Los cuidadores familiares que atienden a dicha población experimentan cambios a nivel personal, familiar, laboral y social' ${ }^{2}$ ya que, las personas en tratamiento de diálisis se vuelven más frágiles y requieren de cuidados más complejos a largo plazo debido al progreso de su enfermedad; a mayor dependencia por parte de la persona que recibe diálisis, mayor el grado de sobrecarga ${ }^{3}$ y a mayor grado de sobrecarga se afecta el compromiso en el cuidado del receptor ${ }^{4}$ y de sí mismo. Por ello, el ejercer el rol como cuidadores familiares requiere conocimientos y habilidades específicas.

La carga es una respuesta "bio-psicosocial" provocada por el tiempo dedicado a sí mismo, y al cuidado, compromisos sociales, estado de salud y económico, y la "tensión emocional" utilizan estrategias de afrontamiento para prevenir o disminuir los efectos de la carga que generan sus responsabilidades podría desarrollar agotamiento psicológico. De acuerdo con la definición de los Descriptores en Ciencias de la Salud (DeCS) el agotamiento psicológico es una "reacción excesiva al estrés causado por el entorno de uno que puede caracterizarse por sentimientos de agotamiento emocional y físico, junto con un sentimiento de frustración y fracaso" ${ }^{\prime \prime}$. Si se identifican las estrategias de afrontamiento adaptativas y mal adaptativas se pueden lograr cambios a través del tiempo y el impacto tanto en el receptor del cuidado como en los cuidadores familiares ${ }^{7}$. Williams et al. definen las estrategias de afrontamiento adaptativas como "formas saludables de lidiar con el estrés, lo que implica ser conscientes de los factores estresantes e intentar reducir sus resultados negativos" ${ }^{\prime \prime}$ mientras que las estrategias de afrontamiento mal adaptativas son "formas poco saludables de lidiar con el estrés en las que un individuo busca ignorar o negar que existen factores estresantes $"$.8.

Debido a la poca literatura encontrada por las investigadoras relacionada a las estrategias de afrontamiento para lidiar con la sobrecarga se optó por realizar un estudio cualitativo, con el fin de levantar datos en Puerto Rico desde la perspectiva de cuidadores familiares. Por consiguiente, la pregunta central fue: ¿Cuáles son las estrategias de afrontamiento implementadas por los cuidadores familiares de pacientes con enfermedad renal en tratamiento de diálisis para lidiar con la sobrecarga? La misma va de la mano con el propósito, explorar las estrategias de afrontamiento (y su contexto) implementadas por los cuidadores familiares de pacientes con enfermedad renal en tratamiento de diálisis para lidiar con la sobrecarga. Algunas de las subpreguntas guías se encuentran en la Tabla 1.

\section{Material y Método}

\section{Diseño}

Se realizó un estudio cualitativo con un diseño fenomenológico-descriptivo para comprender el significado de las experiencias y percepciones de los cuidadores familiares de pacientes con enfermedad renal en tratamiento de diálisis. Este paradigma constituye un medio para llegar a profundizar en fenómenos que han sido poco estudiado y pretende describir y entender las perspectivas de los cuidadores familiares?. 


\section{Participantes del estudio}

El estudio se realizó en el Centro Fresenius Kidney Care Los Paseos en Puerto Rico. El método de muestreo utilizado fue no probabilístico por conveniencia ${ }^{10}$, ya que, el Centro Fresenius Kidney Care nos proveía un ambiente controlado que requirió de una persona enlace [la Trabajadora Social]. Esta profesional al conocer los participantes ayudó a identificar a posibles candidatos o candidatas. De modo que se logró reclutar la muestra más rápido en un intervalo de tiempo determinado. Hubo una población constante de 10 cuidadores familiares que visitan la clínica de diálisis varios días a la semana. Los participantes fueron seleccionados a base de los siguientes criterios de inclusión:

- Mujeres y hombres >21 años de edad.

- Cuidadores familiares de una persona con diagnóstico médico de enfermedad renal crónica en estadio V.

- Cuidadores familiares informales $>3$ meses.

- Puntuación de >56 puntos (carga intensa) en la escala de Sobrecarga del Cuidador de Zarit versión en español. Esta escala ha sido la más aplicada internacionalmente para medir el nivel de carga en cuidadores informales ${ }^{7,11,12}$.

- Capacidad para leer, entender, consentir y contestar preguntas.

- Personas hispanas de otros países que hablaran español.

- Aceptar que la entrevista fuera grabada en audio.

Este estudio recibió la aprobación del Comité de Derechos Humanos de la institución educativa (Protocolo \#7530119). A cada participante se le explicó en qué consistía la investigación, su propósito, los beneficios y riesgos; así como la protección de la confidencialidad y privacidad de la información compartida con las investigadoras. Se le asignó a cada participante un pseudónimo para proteger su identidad.

\section{Técnicas de recogida de información}

Se utilizó una guía de entrevista con sub-preguntas para conocer el trasfondo de las experiencias individuales de los cuidadores familiares (ver Tabla 1). Se discutió y se firmó el consentimiento informado. Luego la investigadora principal realizó las entrevistas semiestructuradas con los cuidadores familiares desde octubre a diciembre de 2019 y en marzo de 2020 las investigadoras concordaron que se había alcanzado la saturación ${ }^{13}$. Las entrevistas se realizaron en un lugar
Tabla 1. Enfoque y Preguntas Semi-estructuradas en la Guía de Entrevista.

\begin{tabular}{|c|c|}
\hline Enfoque & Preguntas \\
\hline $\begin{array}{l}\text { 1. Cuidadores } \\
\text { familiares de } \\
\text { pacientes con } \\
\text { enfermedad renal } \\
\text { en tratamiento } \\
\text { de diálisis }\end{array}$ & $\begin{array}{l}\text { - ¿Desde cuándo usted es cuidador o cuidado- } \\
\text { ra de su familiar? } \\
\text { - ¿Cómo se decidió que usted fuera la persona } \\
\text { cuidadora? } \\
\text { - ¿Cuántos días a la semana y horas cuida } \\
\text { usted a su familiar en el hogar? } \\
\text { ¿Cómo describe un día típico como cuidador } \\
\text { o cuidadora? }\end{array}$ \\
\hline $\begin{array}{l}\text { 2. Preparación } \\
\text { para asumir la } \\
\text { responsabilidad } \\
\text { como cuidadores } \\
\text { familiares }\end{array}$ & $\begin{array}{l}\text { - ¿Cómo se preparó para asumir la responsa- } \\
\text { bilidad de cuidar? } \\
\text { ¿Quién (es) le ayudó? } \\
\text { - ¿Qué conoce de la enfermedad renal? } \\
\text { - ¿Qué conoce del tratamiento de diálisis? }\end{array}$ \\
\hline $\begin{array}{l}\text { 3. Experiencia al } \\
\text { ejercer el rol } \\
\text { como cuidadores } \\
\text { familiares }\end{array}$ & $\begin{array}{l}\text { - ¿Cómo ha sido su experiencia como cuidador } \\
\text { o cuidadora? } \\
\text { - Hábleme de las cosas positivas que encuen- } \\
\text { tra al cuidar su familiar. } \\
\text { - Hábleme de las cosas "no tan positivas" que } \\
\text { encuentra al cuidar su familiar. }\end{array}$ \\
\hline $\begin{array}{l}\text { 4. Ejercer el rol } \\
\text { como cuidadores } \\
\text { familiares }\end{array}$ & $\begin{array}{l}\text { - ¿Cómo se siente usted cuando le brinda cuida- } \\
\text { dos a su familiar? } \\
\text { - ¿Qué usted hace cuando le vienen pensamien- } \\
\text { tos negativos sobre el familiar que cuida? } \\
\text { - ¿Cómo cuidador o cuidadora primario, cuan } \\
\text { cargado/a usted se siente en estos momentos? } \\
\text { ¿Cuáles son las cosas o deberes que lo/a } \\
\text { mantienen cargado/a? }\end{array}$ \\
\hline $\begin{array}{l}\text { 5. Realización de } \\
\text { actividades para } \\
\text { lidiar con la carga }\end{array}$ & $\begin{array}{l}\text { - ¿De qué manera (estrategias) usted utiliza } \\
\text { para afrontar el sentirse cargado? } \\
\text { - Deme ejemplos de algunas estrategias que } \\
\text { utiliza. } \\
\text { - ¿Dónde las aprendió? } \\
\text { ¿Cuán efectivas son en ayudarle a bajar o } \\
\text { aliviar la carga? } \\
\text { ¿Qué estrategias usted ha utilizado, pero } \\
\text { entiende que no le han funcionado para dismi- } \\
\text { nuir o aliviar la carga? }\end{array}$ \\
\hline $\begin{array}{l}\text { 6. Ser buenos } \\
\text { cuidadores } \\
\text { familiares }\end{array}$ & $\begin{array}{l}\text { - ¿Qué habilidades usted tiene para ser un buen } \\
\text { cuidador o cuidadora? } \\
\text { ¿Qué cosas positivas usted podría decir de } \\
\text { sí mismo/a que son esenciales en un buen } \\
\text { cuidador o cuidadora? } \\
\text { ¿Qué aspectos a mejorar usted ha identificado } \\
\text { en sí mismo? } \\
\text { - ¿Qué necesidades usted entiende deben ser } \\
\text { conocidas y atendidas para usted poder ser un } \\
\text { buen cuidador o cuidadora de su familiar y no } \\
\text { sobrecargarse? } \\
\text { - ¿Hay algo más que quiera añadir? }\end{array}$ \\
\hline
\end{tabular}

privado en la clínica y libre de distracciones, mientras el paciente recibía su diálisis. Los participantes tenían la opción de ser entrevistados en su hogar, pero optaron que la misma fuese en la clínica, ya que, se sentían más cómodos; no querían que el familiar pensara que 


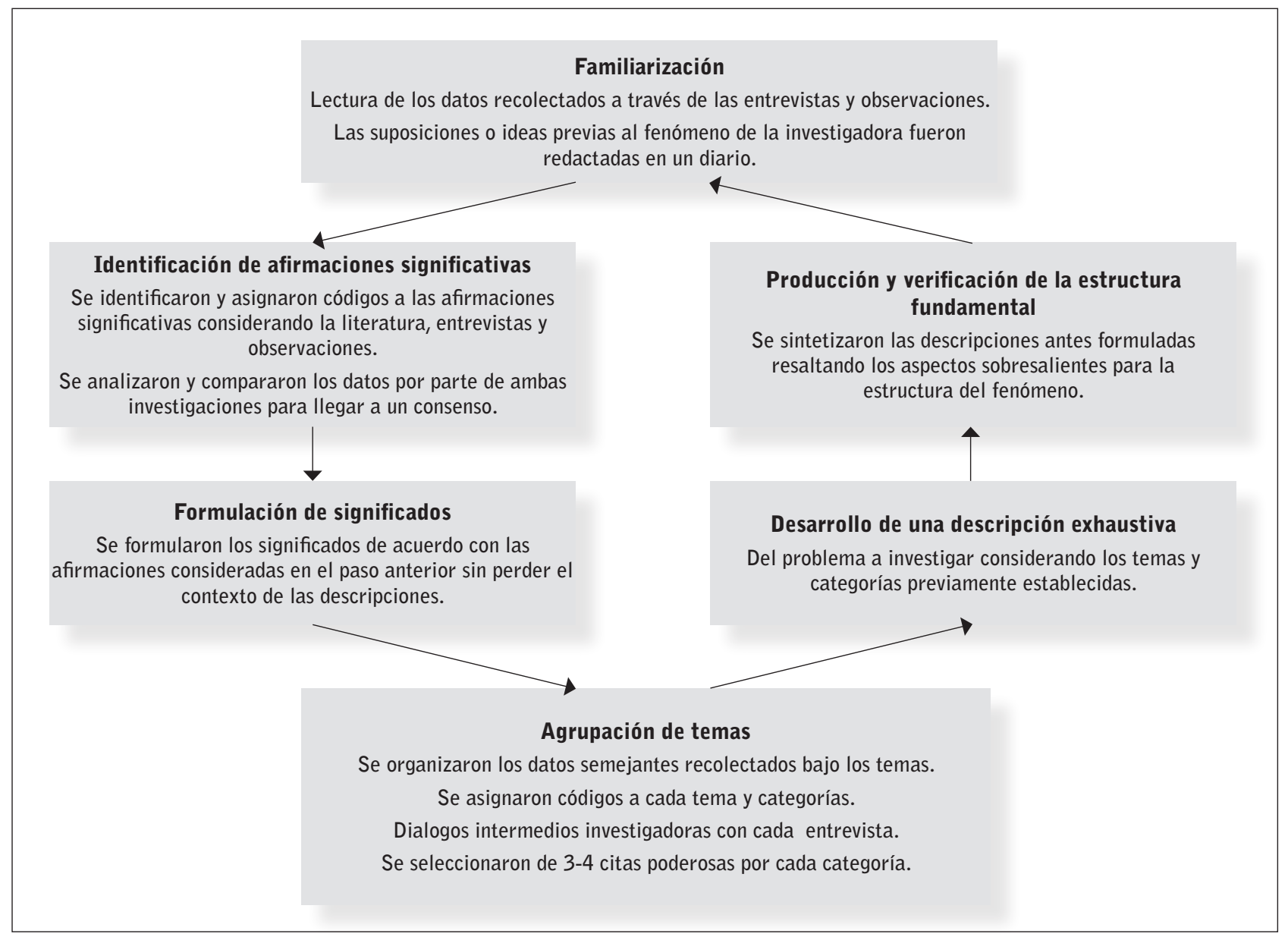

Figura 1. Pasos del Método Fenomenológico Descriptivo de Colaizzi.

era una carga para ellos [cuidadores familiares]. Cada entrevista duró de 60-90 minutos aproximadamente y se grabó en audio. Se utilizó un diario para escribir observaciones y notas reflexivas luego de culminar cada entrevista, que luego fueron dialogadas entre las investigadoras $^{13}$. Esta estrategia provee para la credibilidad, fomenta el rigor y calidad del estudio. Al concluir la entrevista, se recogieron datos sociodemográficos.

Las entrevistas fueron transcritas textualmente. Las entrevistas se realizaron desde octubre a diciembre de 2019 y en marzo de 2020 las investigadoras concordaron que se había alcanzado la saturación; esto es cuando se repite información importante y no hay información nueva ${ }^{14}$. El método fenomenológico-descriptivo de Colaizzi fue utilizado para el análisis (ver Figura 1) ${ }^{15}$. Se identificaron y se asignaron códigos a las afirmaciones significativas considerando la literatura, entrevistas y observaciones. Se formularon los significados sin perder el contexto de las descripciones. Los temas y categorías se agruparon, y se seleccionaron de 3-4 citas por cada categoría. El fenómeno se describió detalladamente considerando los temas y categorías; y se sintetizaron las descripciones resaltando solo los aspectos sobresalientes. Las investigadoras lo realizaron de forma individual y coordinaron reuniones para discutir el análisis, los temas y categorías identificadas para garantizar la credibilidad de los datos.

Se agruparon los datos recogidos por medio de las entrevistas, considerando los factores contextuales que influyeron al establecer las conclusiones sobre la adaptación de los mismos a otros contextos similares. En cuanto a la transferibilidad se proveyó una descripción detallada de las características de la muestra, como fue seleccionada, los datos manejados y el análisis. Además se utilizó un diseño descriptivo, por lo que los hallazgos no pueden ser generalizados. Sin embargo, la descripción del proceso que conlleva ser cuidadores familiares, puede proveer información valiosa para los proveedores 
Tabla 2. Datos Sociodemográficos de los Cuidadores Familiares: Antecedentes Personales.

\begin{tabular}{|c|c|c|c|c|c|c|c|c|c|c|}
\hline $\begin{array}{l}\text { ID } \\
\text { Participante }\end{array}$ & Género & Edad & Nacionalidad & $\begin{array}{c}\text { Nivel } \\
\text { educativo }\end{array}$ & $\begin{array}{c}\text { Estado } \\
\text { civil }\end{array}$ & Hijos/a* & $\begin{array}{l}\text { Condiciones } \\
\text { de salud }\end{array}$ & ¿Trabaja? & Ingresos & $\begin{array}{l}\text { Puntos } \\
\text { ESCZ* }\end{array}$ \\
\hline 01 & Mujer & 45 & puertorriqueña & Bachillerato & Casada & $\begin{array}{l}\text { Sí } \\
2\end{array}$ & $\begin{array}{c}\text {-Artritis } \\
\text { Reumatoidea } \\
\text {-Bipolaridad }\end{array}$ & No & $\begin{array}{l}\text { Apenas } \\
\text { suficiente }\end{array}$ & 65 \\
\hline 02 & Hombre & 66 & puertorriqueño & $\begin{array}{c}2 \text { años } \\
\text { de universidad }\end{array}$ & Casado & $\begin{array}{l}\mathrm{Si} \\
0\end{array}$ & $\begin{array}{c}\text {-Efisema } \\
\text {-Corazón } \\
\text {-Acidez estomacal }\end{array}$ & No & Apenas & 79 \\
\hline 03 & Hombre & 66 & puertorriqueño & $\begin{array}{l}\text { Graduado de } \\
\text { escuela superior }\end{array}$ & Casado & $\begin{array}{l}\text { Sí } \\
0\end{array}$ & $\begin{array}{l}\text { Rehusó compartir } \\
\text { la información }\end{array}$ & No & $\begin{array}{l}\text { Apenas } \\
\text { suficiente }\end{array}$ & 65 \\
\hline 04 & Mujer & 44 & dominicana & $\begin{array}{l}\text { Graduado de } \\
\text { escuela superior }\end{array}$ & Casada & No & $\begin{array}{l}\text {-Alta presión } \\
\text {-Endometriosis }\end{array}$ & $\begin{array}{c}\text { Si } \\
\text { Part-time }\end{array}$ & $\begin{array}{l}\text { Apenas } \\
\text { suficiente }\end{array}$ & 94 \\
\hline
\end{tabular}

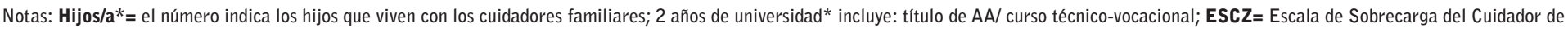
Zarit.

Tabla 3. Datos Sociodemográficos de los Cuidadores Familiares: Antecedentes como Cuidadores Familiares.

\begin{tabular}{|l|c|c|c|c|c|c|c|c|}
\hline $\begin{array}{l}\text { ID } \\
\text { Participante }\end{array}$ & $\begin{array}{c}\text { Preparación académica } \\
\text { como cuidadores } \\
\text { familiares }\end{array}$ & $\begin{array}{c}\text { Tiempo como } \\
\text { cuidadores } \\
\text { familiares }\end{array}$ & $\begin{array}{c}\text { Cuidadores } \\
\text { familiares } \\
\text { principales }\end{array}$ & $\begin{array}{c}\text { Horas de } \\
\text { cuidado }\end{array}$ & $\begin{array}{c}\text { Edad del } \\
\text { RC }\end{array}$ & $\begin{array}{c}\text { Parentesco } \\
\text { con el RC } \\
\text { el RC }\end{array}$ \\
\hline 01 & No & 1 año y l mes & Sí & 24 & 74 & Esposa \\
\hline 02 & No & $>2$ años & Sí & 24 & 58 & Esposo \\
\hline 03 & No & $>2$ años & Sí & 24 & 65 & Esposo & Sí \\
\hline 04 & No & $>2$ años & Sí & 24 & 54 & Sí \\
\hline
\end{tabular}

Notas: $\mathbf{R C}=$ Receptor del Cuidado.

de servicios de salud que trabajan con esta población. Igualmente, dado que las narrativas de las voces de los participantes están explicitas, pueden ser útiles para entender y trabajar con lo que los cuidadores familiares viven con su entorno familiar día a día.

\section{Resultados}

Se fueron reclutando cuidadores familiares hasta obtener saturación con 4 cuidadores ( 2 mujeres y 2 hombres) de 44 a 66 años. El nivel educativo de los cuidadores familiares fue: 2 graduados de escuela superior, 1 culminó su bachillerato y 1 completó 2 años de universidad. El tiempo que Ilevaban como cuidadores familiares, tres de ellos/a coincidieron en llevar $>2$ años, mientras que una cuidadora familiar llevaba un año y 1 mes. Todos los participantes eran cuidadores familiares principales a tiempo completo, vivían con el receptor del cuidado y su parentesco fue de esposo 0 esposa. Los 4 cuidadores familiares afirmaron que sus ingresos eran a penas suficientes. No se les solicitó una cantidad en específico. Las (Tablas 2 y 3) muestran otras características sociodemográficas de los cuidadores familiares.

Luego de llevar a cabo el análisis de cada transcripción considerando el trasfondo de las experiencias de los cuidadores familiares y el propósito del estudio se establecieron 6 temas y 18 categorías. Los temas principales fueron: Inicio como cuidadores familiares, Vivencias como cuidadores familiares, Perspectivas como cuidadores familiares, Sobrecarga y Estrategias de afrontamiento, Necesidades de cuidadores familiares y Receptor del cuidado. Las categorías (ver Figura 2) serán discutidas junto a los temas principales.

\section{Inicio como cuidadores familiares}

El inicio como cuidadores familiares es una etapa en la vida que no se olvida. Las declaraciones de los participantes recordaban con exactitud el tiempo que llevaban 


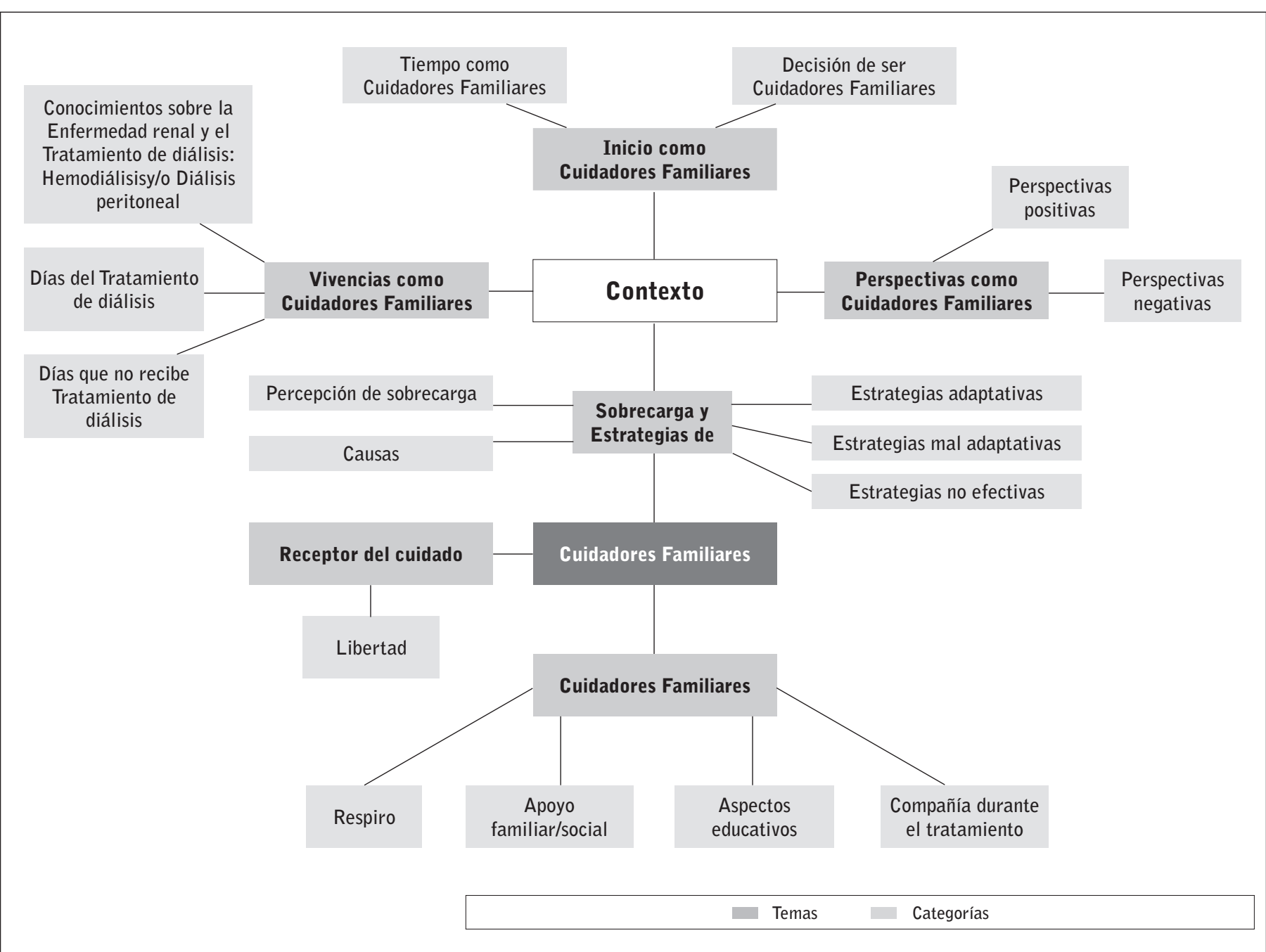

Figura 2. Temas y Categorías.

cuidando. Los mismos/a afirmaron: "Eso fue en Auxilio Mutuo [hospital] en el 2015. En junio, junio de 2015" (02); "Desde el 2009, diciembre 14..." (04); "6 años" (03). Además, el llevar a cabo el rol como cuidadores familiares conllevó cambios muy notorios en sus vidas. Un cuidador familiar indicó: "...yo tengo que reestructurar mi vida, en base a lo que dejé de hacer que iba hacer por ella" [gestos de angustia] (02); mientras que una cuidadora familiar expresó: "...te cambia la vida por completo" (04).

La decisión de ser cuidadores familiares fue compleja e incluso en algunos casos simplemente expresaron que "les tocó". Los cuidadores familiares expresaron: "Te tocó, te tocó" [gestos con las manos] (01); "...es lo que me ha tocado. Sea para bien o para mal... es lo que me ha tocado" (02); "...siempre me toca a mí todo" (04). De igual forma, los participantes afirmaron que tomaron el rol como cuidadores familiares porque les correspondía como esposos o esposas: "Tomé este rol porque soy el esposo..." (03); "...esa es mi responsabilidad" [firmemente y con autoridad] (02); "...él es mi esposo y uno se casa en las buenas y en las malas, para toda la vida". "Es mi obligación... [silencio prolongado]" (04). También, el tomar la decisión de ser cuidadores familiares abarcó el reciprocar lo recibido. Una de las cuidadoras familiares expresó: "Yo enfermé joven..." "Tú sabes, él me cuidó, el me cargó, él me cogía al hombro, me llevaba al baño... Sabes... ¿Cómo yo no voy hacer eso con él?" (01).

\section{Vivencias como cuidadores familiares}

Se exploró en los cuidadores familiares su conocimiento sobre la enfermedad renal y el tratamiento de diálisis (hemodiálisis y/o diálisis peritoneal), y sus funciones y deberes durante los días del tratamiento de diálisis y 
los días en los cuales el receptor del cuidado no recibía tratamiento. Los conocimientos sobre la enfermedad renal de acuerdo a las declaraciones de los cuidadores familiares fueron variados. Dichos conocimientos se vieron influenciados por las experiencias de los cuidadores familiares, la formación militar, el proceso de aprendizaje, la autoeducación, lo que el receptor del cuidado verbalizaba, y otros simplemente aprendieron en la sala de espera escuchando otros cuidadores o cuidadoras. Dos de los cuidadores familiares expusieron que anteriormente se habían dedicado a cuidar a algún familiar y además, tenían formación militar. Uno de ellos verbalizó: "...yo cuidé a papi..." "...toda esa experiencia me llevó hacer más, más este... Ehh, ehh, proactivo con ella" "...ya tenía experiencia, ya tenía una base..." "Y entiendo que la formación militar también me ayudó bastante..." (02). Pero hizo hincapié en que aunque tenía dicha experiencia, su conocimiento sobre la enfermedad renal era muy poco o nada y su conocimiento sobre el tratamiento de diálisis era a base de lo que el receptor del cuidado le verbalizaba. Por el contrario, otro de los cuidadores familiares expresó:

"Cuando mi mamá cayó en diálisis yo era el que la dializaba...". "Ehh, después cayó mi suegra en hemodiálisis y ahora cayó mi esposa en hemodiálisis. Y eso me ha dao una basta experiencia cómo bregar con un paciente renal". "...eso toma tiempo aprenderlo y es en, en español "on the job training" [entrenamiento en el trabajo]. Según usted va practicando, usted va mejorando su función como cuidador". (03)

Los cuidadores familiares refieren no tener un conocimiento a su juicio apropiado, como así lo dejó saber una de las cuidadoras familiares quien indicó: "Pues mira lo poco que conozco es lo que he ido aprendiendo en el transcurso" "...requiere unos cuidados especiales" (01), mientras que su conocimiento sobre el tratamiento de diálisis era limitado, expresó: "No conozco mucho. Sé que lo conectan a esa máquina, que eso le saca el exceso que tiene de líquidos. Que esa máquina le limpia la sangre. Este... Que hace la función del riñón. Es lo, lo que conozco". "Te digo, muchas de las cosas que yo aprendo ha sido en esa sala de espera, escuchando a otros pacientes..." "...uno aprende de boca en boca" [gestos faciales de incomodidad] (01).

Dedicarse a cuidar conlleva múltiples acciones y toma de decisiones durante los tres días del tratamiento de diálisis. En dichos días una de las cuidadoras familiares refirió que no solo se hacía cargo del cuidado de su esposo, sino que también ejercía su rol como madre (01). Varios cuidadores familiares expresaron que ya era una "rutina"
$(02,03$ y 04), el tener que levantarse temprano, preparar la comida, las meriendas, administrar los medicamentos, etc; para luego dirigirse a la clínica y al salir, continuar con sus quehaceres y cuidados. Algunos cuidadores familiares llevaban a cabo diligencias o trabajos que tenían pendientes: "La traigo aquí... de aquí este, estoy a veces conversando un rato con los, con los pacientes, o con los otros cuidadores y me voy. Me voy pa casa o hacer gestiones. 0 sea, ir al correo, pagar deudas, hacer compra". "[Realiza]...los trabajo que tengo pendiente..." (02); mientras que otra cuidadora familiar afirmó: "...tengo que atender el negocio, pequeño negocio que tenemos de plomería que yo soy quien coordino los trabajos..." "Estoy pendiente a los empleados. Soy quien recibe las, las quejas, encargarme de cobrar, de todo" [gestos faciales de frustración] (04).

Durante los días que el receptor no recibía diálisis, los cuidadores familiares cumplían con sus trabajos, desempeñaban gestiones del hogar y diligencias, coordinaban citas médicas, entre otros; pero todo esto era posible, si el receptor del cuidado se encontraba en un estado de salud óptimo dentro de su condición. Una cuidadora familiar lo explicó de la siguiente manera: "...martes y jueves dependo de cómo él amaneció después de esa diálisis" (01). De igual forma, afirma otro cuidador familiar: "Si ella se levanta mal, se despierta mal por decirlo así, este y está un poquito floja de sus fuerzas pues entonces, no hago nada afuera..." "Si yo estoy afuera, ella me dice: No me siento bien hoy, esto y lo otro..." "Yo corto mi trabajo y arranco, y me voy" [gestos faciales de preocupación] (02).

\section{Perspectivas como cuidadores familiares}

Las perspectivas como cuidadores familiares pueden ser variadas y consideradas desde aspectos positivas y negativas. La primera reacción de los cuidadores familiares al indagar sobre los aspectos positivos de ejercer el rol como cuidadores familiares fue: "...es difícil ver algo positivo. Por más que uno quiera ser positivo..." (01); "...positivo yo creo que no hay nada" [firmemente] (02). Al continuar la entrevista, los mismos/a consideraron otros aspectos que habían pasado por alto, tales como: sentimientos de tranquilidad, seguridad, bienestar y satisfacción, conocer otras personas, cercanía y comunicación con el receptor del cuidado. Algunas expresiones sobre estos aspectos incluyen: "...yo me siento más tranquila si lo estoy cuidando yo" [gestos con las manos señalándose el pecho] (01); "Ehh, quizás lo único positivo que he conocido otras personas" (02); "Hay una relación mucho más cerca entre el paciente y el cuidador..." y "...hay mucho diálogo" (03); 
"Ahora valoro más todo lo que tengo. Lo valoro más a él..." [tristeza] (04).

Por otro lado, las perspectivas negativas de los cuidadores familiares fluyeron con más facilidad en las entrevistas, en comparación con las perspectivas positivas. Los cuidadores familiares las describieron como "...es mucho" (01), "...frustrante...", "...estresante..." (03), "difícil" (02, 03 y 04), "...fuerte..." (01 y 04), "agotador" (03 y 04), "sofocante" [gestos con las manos hacia el pecho] (04), etc. También resaltaron la conducta del receptor del cuidado como "...los estados emocionales del paciente" "que a veces lo drenan a usted como cuidador" (03);"... soportar su, su... Sus quejas, soportar su mal humor, soportar este, la familia que no entiende" [gestos faciales de molestia] (02). De igual forma, los cuidadores familiares indagaron sobre los cambios que ocurrieron en su relación matrimonial: "...desde que ella enfermó pues no hay ninguna relación" "...conyugal como tal" (02); "... ya él no duerme conmigo" (04). La poca disponibilidad de tiempo personal promovió que una de las cuidadoras familiares expresara su sentimiento más profundo: "... ya mi tiempo dejó de ser mío" [gestos faciales tristeza] (01).

\section{Sobrecarga y Estrategias de afrontamiento}

La sobrecarga se reconoce como algo común en la vida de los cuidadores familiares. Sus vivencias son difíciles y dolorosas como lo indicaron algunos participantes: "Hay momentos en que me siento así, este... Como que es demasiado. Como que... Te abruma, te, te sientes demasiado cargado" [gestos con las manos y faciales de frustración] (01); "Si vamos en escala del 1 al 10 estoy hoy como un $8^{\prime \prime}(03)$. Otra cuidadora familiar verbalizó: "...no te voy a negar, me siento super cargada" (04). Dos cuidadores familiares refirieron que la carga era como una frustración (02 y 03). Para tres cuidadores familiares su carga se aumentaba por las responsabilidades que tenían que realizar (01, 03 y 04). Un aspecto que resultó ser de gran importancia para los cuidadores familiares fue el compromiso del receptor del cuidado hacia su propia salud. Algunos cuidadores afirmaron que este hecho, de alguna manera aumentaba su percepción de carga o frustración. Un cuidador familiar afirmó su frustración y las razones indicando: "Frustrado porque es que, tú quieres ayudar a una persona, y la persona no dejarse ayudar de lleno, pues te frustra. Te frustra porque osea, yo entiendo que lo mejor para ella es esto, porque ella quiere hacer esto" "...pero a mí lo que, lo que me carga es que me exija" [gestos con las manos] (02). Otro cuidador familiar concuerda con lo dicho:
"... a veces el paciente no es cooperador. A veces el paciente este... Es retador, a veces el paciente no es buen oyente. A veces el paciente es contradictorio y así sucesivamente pues llega el momento que usted cai en una crisis fuerte porque ve que no hay cooperación ni aún del paciente". "Y es frustante porque usted está dando el 100 porciento y la persona que es la que tiene que dar el 100 porciento no lo está dando" [gestos faciales de frustración, disgusto e incomodidad] (03).

Cuando se exploró el tema de las estrategias adaptativas los cuidadores familiares expresaron las siguientes: "ejercicios de respiración y físico", "buscar ayuda de profesionales de la salud (psicólogo(a)/psiquiátra)", "la oración y la fe", "actitud positiva ante todo", "trabajar en la finca" y "tejer". Un cuidador familiar expresó: "...yo lo agarro es el trimmer [podador], el machete y me voy a dar, a desquitarme con el pasto..." "Y libero fuerzas y me canso, y ya todo se va..." [gestos faciales de tristeza] (02). Dicha estrategia es efectiva para él: "Son efectivas porque me ayudan $\mathrm{a}$, a seguir aunque a veces pasando trimmer, tirando machetazos empiezo a llorar y a, y a desahogarme". Por otro lado, una cuidadora familiar afirmó: "...lo más que me distrae es tejer, me encanta crear" [sonríe]. "Eso me bloquea porque, este... Tengo que estar contando cada puntada" (04), afirmó que era "super efectivo..." y la recomendaba. Otros cuidadores familiares expusieron que el hacer un balance (04), y "... hacer una cosa a la vez..." (03) aliviaba su carga.

Fueron muy variadas las respuestas de los cuidadores familiares, pero coincidieron en la oración y la fe. Los cuidadores expresaron: "Oro mucho, soy una persona que creo mucho en orar..." "Y en poner mis cargas en las manos de Dios" (01); "A veces me pongo a orar y esto, y... Y, y canalizo eso seguido" (02); "Si no fuera por mis creencias cristianas pues yo creo que ya me hubiera rendido" (03). Por consiguiente, también coincidieron en buscar ayuda de parte de profesionales de la salud (psicólogo(a)/psiquiatra) (01 y 02) y llevar a cabo actividades que no eran habituales $(02,03$ y 04$)$. El realizar estrategias de afrontamiento adaptativas puede ser beneficioso, pero en ocasiones no son suficientes; como una cuidadora familiar expresó: "Bueno son bastante efectivos, pero hay momentos, hay días que no, que ni siquiera eso es... suficiente" $(01)$.

Al explorar las estrategias mal adaptativas, los cuidadores familiares expresaron su sentir indicando: "dejarlo todo [terminar la relación con el receptor del cuidado]", "evitar la comunicación con familiares" (04) o "asumir conductas de riesgo". El dedicarse a cuidar a una perso- 
na es muy agotador y hay momentos en su vida de querer renunciar. Tal como afirmó un cuidador familiar: "...yo he tenido momentos en que mira dejar todo y arrancar..." "A veces me dan ganas de dejarla y se acabó to" [gestos con las manos] (02). En ocasiones pueden acudir a comportamientos de riesgo, tales como: "...yo antes me iba en el carro y, y la tentación del carro, meter la pata y fummm, y seguir más, más rápido, y eso conlleva errores" (02); "...una vez me corté el pelo bien cortito de un coraje que cogí no se por qué. Me paré en el espejo, cogí la tijera y me recorté" (04). Otro cuidador compartió su experiencia de como el viajar no fue una estrategia efectiva:

"...yo he viajado con ella a pa diferentes estados de la nación americana y una vez que estamos allá tengo que hacer coordinación para dializarla y entonces a veces se descompensa porque no la dializan bien, entonces hay que hospitalizarla y caemos de nuevo en un círculo vicioso peor del que había cuando estaba estable" (03).

Dos de los cuidadores familiares indicaron que no hacen uso de estrategias mal adaptativas (01 y 03).

\section{Necesidades de cuidadores familiares}

Las necesidades expresadas por los cuidadores familiares fueron: respiro, apoyo familiar/social, aspectos educativos y compañía durante el tratamiento. En cuanto al respiro, un cuidador familiar compartió su sentir: "Bueno yo quisiera decir que ehh, si yo consiguiera a una persona que de los tres días me relevara un día". "Y desde el punto de vista mío, no es mucho pedir [afirma con la cabeza no]. Yo tuviera un alivio" (03). Los cuidadores familiares destacaron la necesidad de recibir apoyo de sus familiares y de la institución en donde le brindaban los servicios de diálisis a su familiar. Dos cuidadores familiares afirmaron que debería de haber una mejor comunicación de parte de la institución (01 y 03). Expresaron que se encargaban solos de todos los cuidados que requería el paciente, sin apoyo (01, 02, 03 y 04). Una cuidadora familiar expresó: "....la familia debería de ayudar también" y de esta manera ella podría cumplir con otras responsabilidades y el receptor del cuidado se beneficiaría al compartir con ellos/a (04). Además, un cuidador familiar consideró que el saber en dónde se encuentran los grupos de apoyo y cómo accesarlos le podría ser beneficioso (02). Solo un cuidador estuvo en desacuerdo (03) como atender esta necesidad.

Los cuidadores familiares fueron bien específicos en detallar lo que les gustaría recibir por parte de la clínica incluyendo más información y talleres relacionados a:
¿Cómo lidiar con la carga?, ¿Cómo lidiar con las cargas emocionales?, ¿Qué conlleva el cuidar a una persona enferma?, Cuidados efectivos y ¿Qué hacer en caso de que el paciente se complique? También el recibir educación sobre: ¿Qué es la enfermedad renal? y ¿En qué consiste el tratamiento de diálisis? Una de las cuidadoras familiares expresó: "...tenemos un grupito de cinco que siempre estamos juntas, pero tú ves diferentes, siempre hay cuidadores ahí. Que yo sé si se prestan ese tipo de taller, van este... Va a ver quorum" (01). Otro cuidador familiar afirmó que sería bueno que los talleres o charlas se brindaran en la misma clínica; y que se utilizaran videos (02). También el orientarlos sobre las ayudas que podrían recibir del estado, en aspectos económicas y personales (02 y 04); una cuidadora enfatizó: "...debe de haber ayuda económica para poder sobrellevar porque a veces uno deja de trabajar para cuidarlo" (04).

El apoyo emocional ocupa un lugar importante en las necesidades de los cuidadores familiares $(01,02,03$ y 04$)$. Dos de los cuidadores mostraron una gran inquietud sobre el estar junto al receptor del cuidado mientras recibía el tratamiento. Estos sustentan que podría ser beneficioso tanto para ellos/a para tener una mejor comprensión del tratamiento, como también para el/la paciente (02 y 04). Uno/a de ellos [cuidador] expresó: "En Estados Unidos tú entras con el paciente al centro de diálisis y estás con él ahí. ¿Y por qué aquí en Puerto Rico no?" [gestos con las manos] (02).

\section{Receptor del cuidado}

El tema receptor del cuidado surgió como un hallazgo nuevo. De acuerdo con las declaraciones de los cuidadores familiares entrevistados, se enfatizó el proveerle libertad al receptor del cuidado para que se sintiera útil, y realizara sus actividades y quehaceres. Un cuidador indagó sobre la libertad, soltura y añadió: "...su condición no puede ser base para inutilizarla..." "...cuando tú restringes [gestos con las manos, cerró los puños], tú inutilizas..." (02). De igual manera, otro cuidador familiar coincidió y abarcó la importancia de compartir y realizar salidas, expresó: "... la saco, cosa de que vea cosas nuevas y no esté en una pecera. Sino que tenga libertad de ver cosas diferentes..." (03). Una cuidadora familiar hizo incapié en su comportamiento sobreprotector y refiere reconocer la necesidad de libertad del receptor del cuidado, verbalizó "...soy sobreprotectora con él. Demasiado. Me dice él. Él a veces me dice que quiere salir solo y me da pánico" [gestos con las manos y ojos]. Añadió: "Tendría que mejorar eso. Lo único que se queja de mí... él quiere... Más libertad de poder salir" (04). Fue sorprendente cuando la menciona- 
da cuidadora familiar verbalizó: "Me dice que me tiene miedo a la hora de decirme que quiere ir solo al correo [sonríe]". "Pero me dice que lo quiere hacer... Para él saber y estar seguro de que ya él está $100 \%$ pues recuperado". El receptor del cuidado es limitado y necesita sentirse útil, independiente en ciertas labores.

\section{Discusión/Conclusiones}

El aumento en la prevalencia e incidencia en la población de personas con enfermedad renal en tratamiento de diálisis ${ }^{16}$ requiere la asistencia de cuidadores familiares para satisfacer las necesidades del receptor durante el proceso de enfermedad. Todos los cuidadores familiares entrevistados eran los esposos o esposas, vivían con el receptor del cuidado y brindaban cuidados las 24 horas del día. Khamis Alnazly ${ }^{17}$ identificó en su estudio que vivir con el receptor del cuidado era un factor predictivo de carga y según López García ${ }^{4}$ el hecho de que el cuidado dependiera de una sola persona dificultaba la atención hacia el receptor y también aumentaba la carga. Se encontró que solo una cuidadora familiar trabajaba a tiempo parcial y un cuidador familiar de vez en cuando hacía trabajos. Además, todos los cuidadores familiares reportaron que sus ingresos eran a penas suficientes. Del mismo modo, en otro estudio se evidenció que los cuidadores o cuidadoras que brindaban cuidados y se desempeñaban laboralmente presentaban mayores niveles de sobrecarga, al igual que los cuidadores o cuidadoras que disponían de "bajos ingresos $^{\prime \prime 18}$.

Los cuidadores familiares coincidieron en que no tenían ninguna preparación para ejercer el rol como cuidadores familiares y tres de ellos/a según su percepción no contaban con un conocimiento apropiado sobre los cuidados de un paciente en tratamiento de diálisis; sin embargo, el poco conocimiento que tenían lo habían adquirido dialogando con otros cuidadores o cuidadoras. Dicho hallazgo es respaldado por una investigación en donde se encontró que los cuidadores o cuidadoras aprendían de las experiencias de otros cuidadores o cuidadoras de pacientes con enfermedad renal ${ }^{19}$. Investigaciones previas sugieren que gran parte de la carga que recae en el cuidador o cuidadora es a causa del desconocimiento sobre la enfermedad y los cuidados que requiere el receptor ${ }^{20,21}$.

Los cuidadores familiares entrevistados explicaron que tuvieron que re-estructurar su vida de acuerdo a las necesidades del receptor del cuidado, evidenciado por diferentes estudios ${ }^{22,23}$. Los cuidadores expresaron que se sentían responsables de brindar los cuidados porque era parte del amor y las responsabilidades del matrimonio, y el reciprocar lo recibido. Igualmente, en estudios anteriores los cuidadores o cuidadoras sentían el deber de cuidar a su familiar como una muestra de amor ${ }^{20,24}$. Todos los cuidadores familiares se encontraban en una relación de dependencia porque sus decisiones o acciones dependen del estado de salud del receptor del cuidado. Por ello, los cuidadores familiares no se sentían dueños de su tiempo y de alguna forma habían perdido su autonomía. Esto es consistente con un estudio en donde se obtuvo que las actividades rutinarias de los que cuidan se veían interrumpidas debido a las demandas de cuidado ${ }^{19}$, e incluso tenían que adaptar sus horarios a las necesidades del receptor del cuidado ${ }^{22}$. Los participantes del estudio describieron el brindar cuidados como "frustrante", "estresante", "difícil", "fuerte", "agotador", etc. Similar a estudios anteriores en donde se obtuvo que los cuidadores o cuidadoras reportaron estar "estresados", "enojados" y "frustrados 119,24 , mientras que en otro estudio los cuidadores o cuidadoras expresaron que era "difícil", "abrumador"y "angustiante" ${ }^{\prime \prime}$. Aún con las dificultades, los cuidadores familiares confirmaron que tenían sentimientos de bienestar y satisfacción al brindar los cuidados, al igual que otras investigaciones ${ }^{22,24}$.

En cuanto a la sobrecarga, estudios afirman que es de leve a moderada $25,26,27$; sin embargo, otros estudios concluyeron que es de moderada a severa ${ }^{28,29}$. Además de multicausal, provocada por la falta de tiempo para ejercer otros roles ${ }^{20,22}$, las responsabilidades del cuidado ${ }^{30}$, las exigencias del receptor, compromisos laborales y el aspecto económico. Dos de los cuidadores familiares masculinos en este estudio declararon que la conducta y el comportamiento por parte del receptor del cuidado hacia su propia salud aumentaba su frustración, lo cual coincide con hallazgos previos mencionados ${ }^{24}$.

Los cuidadores familiares entrevistados implementaban estrategias de afrontamiento, incluyendo ejercicios de respiración, búsqueda de ayuda de profesionales de la salud (psicólogo(a)/psiquiátra), la oración y la fe, actitud positiva ante todo, trabajar en la finca, tejer y llevar a cabo actividades no habituales. Estos hallazgos fueron consistentes con los de otros estudios, en los cuales se encontró que la fe y la oración ${ }^{17,19,24,31}$ y los ejercicios físi$\cos ^{17,24}$ aliviaban la percepción de la carga; mientras que otros afirmaron que las estrategias que utilizaban eran: búsqueda de redes de apoyo ${ }^{21,26}$, leer ${ }^{20}$, ver películas, almorzar con amistades y la educación $n^{5,32}$. En un estudio realizado por Khamis Alnazly ${ }^{26}$ con 139 cuidadores o cuidadoras con el fin de evaluar el efecto de la educación en el nivel de la carga en los cuidadores o cuidadoras, con- 
cluyó que los programas educativos aumentaban el conocimiento de la enfermedad, mejoraban las habilidades y capacidad para ofrecer atención de calidad hacia los receptores del cuidado, mientras los mismos cuidaban de su salud. Este aspecto es relevante en el presente estudio, ya que, los cuidadores familiares reconocen que tienen necesidades de aumentar conocimientos y manejar la condición renal del receptor.

Solo tres estrategias de afrontamiento mal adaptativas fueron identificadas, incluyendo: "dejarlo todo", "evitar la comunicación con familiares" o "asumir conductas de riesgo"; mientras que en otros estudios los cuidadores o cuidadoras optaban por la evitación ${ }^{33}$ y el distanciamiento $^{34}$. La única estrategia de afrontamiento que se identificó por uno de los participantes que no era efectiva fue viajar. De hecho, hay evidencia de que aunque se provee apoyo social para continuar el tratamiento si se realizan viajes, el hecho de que el personal del centro no tiene conocimiento sobre el caso de la persona en tratamiento, ocasionaba "preocupación" en el cuidador o cuidadora24.

Todos los cuidadores familiares fueron precisos en indicar que desempeñaban solos el rol como cuidadores familiares y que necesitaban apoyo de parte de los familiares. Una investigación resaltó que el recibir ayuda de la familia disminuía el estrés en los cuidadores o cuidadoras ${ }^{24}$. Aunque los cuidadores familiares no abordaron específicamente cambios en su estado físico, si afirmaron la necesidad de recibir ayuda psicológica. En varios estudios se identificó que los cambios que enfrentaban los cuidadores o cuidadoras les afectaba tanto físico como psicológicamente $21,31,35$.

Entre las limitaciones del estudio se incluye el haber tenido un solo escenario para reclutar participantes. Aunque se logró solo la participación de 4 personas la verdadera importancia fue la riqueza de los datos que se generaron mediante conversaciones a profundidad con los participantes. Una segunda limitación fue la selección de candidatos que solo hablaran el idioma español. Las perspectivas de otros cuidadores familiares que no hablasen español no pudieron ser escuchadas.

En conclusión, la población de personas con enfermedad renal en tratamiento de diálisis requiere la asistencia de cuidadores familiares durante el proceso de enfermedad, ya que, brindan cuidados las 24 horas del día lo que aumenta la carga. En ocasiones el implementar estrategias de afrontamiento adaptativas no fue suficiente para lidiar con la carga, por ello es necesario brindarles seguimiento mediante evaluaciones periódicas. Algunas recomendaciones para futuros estudios serían el identificar el nivel de sobrecarga y las estrategias de afrontamiento que podrían ser efectivas de acuerdo con las necesidades de los cuidadores familiares, los profesionales de enfermería y el equipo interdisciplinario. Dado que los cuidadores familiares coincidieron en que no tenían ninguna preparación para ejercer el rol como cuidadores familiares y según su percepción no contaban con un conocimiento apropiado sobre los cuidados de un paciente en tratamiento de diálisis. Para atender este hallazgo, se podrían implementar intervenciones con mayor efectividad y colaborar en educaciones que empoderen y ayuden a los cuidadores familiares a cuidar de sí mismos y de la persona a su cargo para una mejor calidad de vida y de cuidado. Por otro lado, se recomienda realizar nuevas investigaciones del tópico tomando en consideración el sexo y género, y las diferencias en el rol como cuidadores familiares. Esto podría ser útil para que el personal administrativo de los centros que brindan servicios de diálisis pueda trabajar protocolos individualizados en los cuales se incluya la participación de los cuidadores familiares en la preparación y proceso del tratamiento de hemodiálisis. También podrían implementar instrumentos de evaluación para identificar las necesidades de los cuidadores familiares que ellos/a podrían trabajar. Además, deben de buscar recursos que pudiesen ayudar a los cuidadores familiares y a los pacientes que reciben el tratamiento de diálisis a trabajar con el aspecto de la sexualidad en el matrimonio, ya que, es un área que se ve afectada y es de importancia en una relación.

El acercamiento metodológico de la fenomenología descriptiva utilizada en este estudio nos permitió obtener una visión inicial del fenómeno de sobrecarga desde la perspectiva de los cuidadores familiares en el contexto de Puerto Rico. Sin embargo, para continuar expandiendo el conocimiento sobre este fenómeno se recomienda el uso de la fenomenología interpretativa (FI) para tener una visión más amplia y profunda del tema. Igualmente, se recomienda un seguimiento longitudinal con una muestra de participantes diversos y el uso de múltiples estrategias de recolección de datos para poder capturar la esencia de la experiencia vivida en esta población y sus cuidadores familiares.

\section{Descargo de responsabilidad}

Parte de esta investigación fue aceptada para presentar en el $41^{\circ}$ Foro Anual de Investigación y Educación de la Universidad de Puerto Rico, Recinto de Ciencias Médicas. 


\section{Agradecimientos}

Se le agradece a los cuidadores familiares por su participación, al personal de administración que colaboró de la Clínica Fresenius Kidney Care Los Paseos, y a la Prof. Marian Saade, experta en enfermedades renales en Puerto Rico quien sirvió de puente para la entrada en la facilidad de salud. De igual forma se le agradece a la Sra. Solymar S. Solís Báez por la traducción del resumen de la investigación y colaboración durante el estudio.

Recepción: 04-01-21

Aceptación: 02-04-21

Publicación: 30-06-21

\section{Bibliografía}

1. Delgado I. Dramático aumento de nuevos casos de diálisis [Internet]. San Juan: EI Nuevo Día. 2016 [consultado sep 2018]. Disponible en: https:// www.elnuevodia.com/estilosdevida/saludyejercicios/nota/dramaticoaumentodenuevoscasosdedialisis-2200013/.

2. Yonte Huete F, Urién Pérez $Z$, Martín Gutiérrez M. Sobrecarga del cuidador principal. Rev enferm CyL. 2010;2(1):59-69.

3. Aguilera AI, Castrillo EM, Linares B, Carnero RM, Alonso AC, López $\mathrm{P}$ et al. Análisis del perfil y la sobrecarga del cuidador de pacientes en Diálisis Peritoneal y Hemodiálisis. Enferm Nefrol. 2016 Oct- Dic;19(4):359-65.

4. López García EP. Puesta al día: cuidador informal. Rev enferm CyL. 2016;8(1):71-7.

5. Usman HB, Atif I, Rashid F, Waleed M, Arshad F, Qamar W et al. Assessment of caregiver burden of patients receiving dialysis treatment in Rawalpindi. J Pak Med Assoc. 2017 0ct;67(10):1498- 501.

6. Descriptores en Ciencias de la Salud (DeCS). [consultado 15 feb 2021]. Disponible en: http:// decs2020.bvsalud.org/cgi-bin/wxis1660.exe/decsserver/.
7. Crespo López M, Rivas MT. La evaluación de la carga del cuidador: una revisión más allá de la escala de Zarit. Clin salud. 2015;1:9-15.

8. Williams LA, Graff JC, Wicks MN, Cowan PA, White-Means $S$, Tolley EA. Male caregivers of persons with end stage renal disease: A qualitative study. Nephrol Nurs J. 2017 May-Jun; 44(3):234-42.

9. Polit DF, Tatano Beck C. Nursing research: Generating and assessing evidence for nursing practice. $9^{\text {th }}$ ed. Philadelphia: Wolters Kluwer Health; 2012.

10. Munhall P. Nursing Research: A qualitative perspective. $5^{\text {th }}$ ed. Toronto: Jones and Bartlett; 2012.

11. Albarracín Rodríguez $A P$, Cerquera Córdoba AM, Pabón Poches DK. Escala de sobrecarga del cuidador Zarit: estructura factorial en cuidadores informales de Bucaramanga. Revista de Psicología. 2016;8(2):87-99.

12. Pedraza AM, Rodríguez-Martínez CE, Acuña R. Validación inicial de una escala para medir el nivel de sobrecarga de padres o cuidadores de niños asmáticos. Biomédica. 2013;33:361-9.

13. Nieswiadomy RM, Bailey C. Foundations of Nursing Research. $7^{\text {th }}$ ed. Boston: Pearson; 2018.

14. Shosha, GMA. Employment of Colaizzi's Strategy in Descriptive Phenomenology: A Reflection of a Researcher. Eur Sci J. 2012;8(27):31-43.

15. Morrow R, Rodriguez A, King N. Colaizzi's descriptive phenomenological method. J Psychol. 2015 Aug;28(8):643-4.

16. Cangiano JL. Salud Renal en Puerto Rico. Galenus. 2019;51(2).

17. Khamis Alnazly E. Burden and coping strategies among Jordanian caregivers of patients undergoing hemodialysis. Hemodial Int. 2016;20:8493.

18. Cagan 0, Unsal A, Celik N, Ture A, Culha I, Kok $\mathrm{H}$. Care Burden of Caregivers of Hemodialysis $\mathrm{Pa}$ tients and Related Factors. Int J Caring Sci. 2018 Jan-Apr;11(1):279-84. 
19. Rabiei L, Ali Eslami A, Abedi H, Masoudi R, Reza Sharifirad G. Caring in an atmosphere of uncertainty: perspectives and experiences of caregivers of peoples undergoing hemodialysis in Iran. Scand J Caring Sci. 2016;30:594-601.

20. Williams LA, Graff JC, Wicks M N, Cowan PA, White-Means S, Tolley EA. Male caregivers of persons with end stage renal disease: A qualitative study. Nephrol Nurs J. 2017 May-Jun;44(3):234-42.

21. Guacas Guerra MA. Carga del cuidado de los cuidadores de personas con enfermedad renal crónica, sometidos a diálisis y hemodiálisis en una Unidad renal del municipio de Pasto en el periodo marzo - julio de 2014. UNIMAR. 2016.

22. Ebadi A, Sajadi SA, Moradian ST, Akbari A. Suspended Life Pattern: A Qualitative Study on Personal Life Among Family Caregivers of Hemodialysis Patients in Iran. SAGE. 2018;0(0):1-8.

23. Saborío Morales L, Hidalgo Murillo, LF. Síndrome de Burnout. Med leg Costa Rica. 2015 Mar; 32(1).

24. Turner $C$, Finch-Guthrie P. Experiences of caregivers caring for a family member who is using hemodialysis. Nephrol Nurs J. 2020 Jan-Feb;47(1): 23-34.

25. Gill AS, Singh A, Matreja PS, Gupta AK, Singh N, Khosla PP et al. Assessment of the Quality of Life of Caregiver's of Patients Suffering from Chronic Kidney Disease. BANTAO J. 2011 Jan;9(1):31-5.

26. Khamis Alnazly E. The impact of an educational intervention in caregiving outcomes in Jordanian caregivers of patients receiving hemodialysis: A single group pre-and post test. Int J Nurs Sci. 2018 Mar;5:144-50.

27. Teixidó-Planasa J, Tarrats Velascoa L, Arias Suáreza N, Cosculluela Masb A. Sobrecarga de los cuidadores de pacientes de diálisis peritoneal. Validación de cuestionario y baremos. Nefrología (Madr.). 2018 0ct;38(5):535-44.
28. Bayoumi MM. Subjective Burden on Family Carers of Hemodialysis Patients. $0 \mathrm{~J}$ Neph. 2014 Jun;4:79-85.

29. Mashayekhi F, Pilevarzadeh M, Rafati F. The Assessment of Caregiver Burden in Caregivers of $\mathrm{He}$ modialysis Patients. Mater Sociomed. 2015 0ct; 27(5):333-6.

30. Tong A, Sainsbury P, Craig JC. Support interventions for caregivers of people with chronic kidney disease: A systematic review. Nephrol Dial Transplant. 2008 Jul;23(12):3960-5.

31. Romero Massa E, Maccausland Segura Y, Solórzano Torrecila L. El cuidador familiar del paciente renal y su calidad de vida, Cartagena (Colombia). Salud Uninorte. 2014;30(2):146-57.

32. Ghane G, Ashghali M, Seyedfatemi N, Haghani H. Effectiveness of Problem-Focused Coping Strategies on the Burden on Caregivers of Hemodialysis Patients. Nurs Midwifery Stud. 2016 Jun;5(2):1-11.

33. Menati L, Torabi Y, Andayeshgar B, Khatony A. The Relationship Between Care Burden and Coping Strategies in Caregivers of Hemodialysis Patients in Kermanshah, Iran. Psychol Res Behav Manag. 2020 Feb;13:133-40.

34. Alnazly, E. Coping Strategies and Socio-Demographic Characteristics among Jordanian Caregivers of Patients Receiving Hemodialysis. Saudi J Kidney Dis Transpl. 2016;27(1):101-6.

35. Sajadi SA, Ebadi A, Moradian ST. Quality of Life among Family Caregivers of Patients on Hemodialysis and its Relevant Factors: A Systematic Review. Int J Community Based Nurs Midwifery. 2017;5(3):206-18.

Este artículo se distribuye bajo una Licencia Creative Commons Atribución-NoComercial 4.0 Internacional. https://creativecommons.org/licenses/by-nc/4.0/ 